\title{
Simultaneous Measurements of Antarctic Mesospheric Gravity Waves by Meteor Radar and Lidar
}

\author{
Tadahiko Ogawa ${ }^{1}$, Akio Nomura ${ }^{2}$, Takashi TANAKA ${ }^{1}$, and Kiyoshi IgARAshi ${ }^{1}$ \\ ${ }^{1}$ Communications Research Laboratory, Koganei-shi, Tokyo I84, Japan \\ ${ }^{2}$ Faculty of Engineering, Shinshu University, Nagano 380, Japan
}

(Received September 10, 1988; Revised July 3, 1989)

\begin{abstract}
Simultaneous measurements of high-latitude upper mesospheric gravity waves by a $50 \mathrm{MHz}$ meteor radar and a dye lidar were made at Syowa Station, Antarctica, in 1985. The radar measured nearly north-south components of neutral wind velocities at altitudes of $80-100 \mathrm{~km}$ and at slant ranges of $110-600 \mathrm{~km}$ from Syowa Station, while the lidar measured the sodium density profile and sodium abundance at the same altitudes at the zenith of Syowa Station. From measurements on six nights, it is found that short-period (1-2 hours) and long-period ( $\geq 2$ hours) perturbations of the wind velocity due to gravity waves are well manifested in the sodium abundance and sodium density perturbations, thus suggesting that the response of the neutral winds to gravity waves is fundamentally consistent with the sodium layer response. From a case study, it is demonstrated that during a mediumscale auroral substorm, a strong equatorward wind attaining a maximum of $60 \mathrm{~m} / \mathrm{s}$ appeared in accord with a gradual decrease in sodium abundance. A mechanism explaining this causal relation is unknown.
\end{abstract}

\section{Introduction}

It is now believed that gravity waves play a significant role in the general circulation of the middle atmosphere (e.g., GELLER, 1983; FRITTS, 1984). Gravity waves, mostly coming from the lower atmosphere, manifest themselves as modifications of the upper mesospheric wind (HINES, 1960), the sodium layer at an altitude range of 80-100 km (ROWLETT and GARDNER, 1978) and other physical parameters. Until now, gravity waves in the upper mesosphere have been observed by a variety of techniques, among which both radar (MF, VHF and meteor radars) and lidar have been the most powerful tools for clarifying the morphology and physical processes of gravity waves. Radar can measure neutral wind velocities modulated by gravity waves (e.g., MEEK et al., 1985), while lidar using resonant backscatter from the sodium layer can measure gravity waves as wavelike perturbations of the layer (especially on the bottomside of the layer), and of the sodium abundance (CHIU and Ching, 1978; Gardner and Shelton, 1985; GARDNER and Voelz, 1987). Notwithstanding that a comparison of gravity wave features obtained simultaneously by both techniques is important for understanding the interaction between the 
upper mesosphere and gravity waves, simultaneous experiments have rarely been made.

From simultaneous measurements using meteor radar and lidar systems at mid-latitude, AVERY and TETENBAUM (1983) have shown that a wind shear mechanism may account for the agreement between the altitude of maximum sodium density and that of the zero wind node, and also that density perturbations of the neutral atmosphere reconstructed from meteor winds with periods longer than 3 hours are similar to small-scale fluctuations seen in the sodium profile. These results suggest that simultaneous measurement is important for full understanding of the dynamic response of the sodium layer to gravity waves.

Gravity wave activities in the southern high-latitude sodium layer have been extensively studied by a dye lidar installed at Syowa Station, Antarctica $\left(69^{\circ} 00^{\prime} \mathrm{S}\right.$, $39^{\circ} 35^{\prime} \mathrm{E}$ ), in 1985 . From an analysis of sodium density profile measurements of 42 nights, NOMURA et al. (1989) have found that vertical wavelengths, vertical phase velocities and periods range from 4 to $10 \mathrm{~km}$, from 0.5 to $5 \mathrm{~km} / \mathrm{h}$ and from 1 to 10 hours, respectively. These waves should be also detected by a meteor radar at Syowa Station which can measure horizontal neutral wind components.

This paper describes some results from the simultaneous measurements of 6 nights of the upper mesospheric gravity waves by the meteor radar and lidar systems at Syowa Station, and discusses a relationship between the perturbations of the neutral wind and sodium layer due to gravity waves. Although AVERY and TETENBAUM (1983) paid attention to the long-period ( $>3$ hours) waves, we here consider both the long- and short-period (1-2 hours) waves. It will be found that in addition to the long-period perturbations, the short-period perturbations of the wind velocity are related to those of the sodium abundance and sodium profile.

\section{Experiment}

Neutral winds between 80 and $100 \mathrm{~km}$ altitude were measured by a $50 \mathrm{MHz}$ radar with a nominal peak power of $15 \mathrm{~kW}$ (IGARASHI et al., 1982; OGAWA et al., 1985). This monostatic pulsed-Doppler radar was designed to detect both meteor echoes (meteor radar) and aurorally-associated echoes appearing often in the disturbed $E$-region (auroral radar). An operator can select either of these two functions. The radar has two antenna beams with a crossing angle of about $33^{\circ}$; one toward magnetic south (the GMS beam with an azimuth of $133.7^{\circ}$ from north to east) and the other toward approximately geographic south (the GGS beam with an azimuth of $166.4^{\circ}$ ). In principle, this configuration enables us to determine a twodimensional wind motion in the horizontal plane. Each antenna beam is formed by using three 14-element coaxial collinear antennas and has a beamwidth of about $4^{\circ}$ in the horizontal plane and of about $30^{\circ}$ in the vertical plane.

A minicomputer annexed to the radar controls antenna switching (every 5 minutes in this experiment) and real-time data processing of meteor echoes. For each meteor echo, the time profile of the echo intensity, the line-of-sight velocity of the echo trail, the echo height deduced from the decay-height method, the echo slant 
range and other necessary information were stored on magnetic tapes. The velocity was obtained from the zero-crossings of the Doppler signal having an offset frequency of $40 \mathrm{~Hz}$ which covers velocities between -120 and $180 \mathrm{~m} / \mathrm{s}$ without aliasing. Overall accuracy of the Doppler velocity measurement is estimated to be less than $5 \mathrm{~m} / \mathrm{s}$.

It is noted that wind velocities and directions deduced from meteor radar, especially at auroral-zone latitudes during disturbed geomagnetic conditions, do not always represent real neutral wind motions. This is due to the fact that the movement of a plasma column produced by a meteor is determined by both neutral wind and the ionospheric electric field, which becomes stronger under more disturbed conditions (REID, 1983). Also noted is that when plasma irregularities appear in the $E$-region during meteor radar operation, the radar detects echoes from these irregularities (auroral echoes) in addition to meteor echoes. In this study, auroral echoes and meteor echoes contaminated by auroral echoes were excluded by carefully examining the time profile of each echo intensity stored on magnetic tape, and only reliable meteor echoes were picked up for analysis. This procedure was very easy because meteor echo profiles are essentially different from auroral echo profiles. It is, however, impossible to remove probable effects of ionospheric electric fields upon the measured Doppler velocities of meteor echoes because we have no simultaneous electric field data.

In 1985, a lidar system was installed at Syowa Station and used to observe the nighttime sodium layer during the period from the end of March to the middle of October. The detailed description of the system and some results, including temporal and seasonal variations of the sodium layer and gravity wave activities, have been presented by NOMURA et al. (1987, 1988, 1989). Briefly, the system consists of a transmitter based on a coaxial flashlamp pumped dye laser tuned to the sodium $\mathrm{D}_{2}$ line $(589.0 \mathrm{~nm})$, a Cassegrainian-type telescope of $50 \mathrm{~cm}$ in diameter, photon detection and counting circuits, and a data processing computer. The laser beam was fired toward the zenith with a pulse repetition frequency of $0.5 \mathrm{~Hz}$. One vertical sodium profile with a height resolution of $1 \mathrm{~km}$ was obtained by accumulating the signal returns from 100 laser shots. Successive profiles with a time resolution of about 15 minutes were stored on magnetic tapes for later analysis.

Although our meteor radar and lidar can explore the same altitude range $(80-100 \mathrm{~km})$, the meteor radar observes the areas at slant ranges between 110 and about $600 \mathrm{~km}$ from Syowa Station toward the southeast for the GMS beam and toward the south for the GGS beam, whereas the lidar observes the sky at the zenith of Syowa Station. These configurations mean that the areas viewed with the meteor radar are horizontally separated from the lidar field of view by $63-590 \mathrm{~km}$. For a comparison of gravity waves measured by both techniques, this separation may not be a problem when horizontal wavelengths are long enough; say, of the order of $1000 \mathrm{~km}$. However, when wavelengths are smaller than $1000 \mathrm{~km}$, wind velocity data compiled from meteor echoes at all slant ranges $(110-600 \mathrm{~km})$ may scatter because the size of the meteor radar field of view $(530 \mathrm{~km})$ is comparable to the wavelengths of gravity waves, and therefore a comparison between the meteor and lidar data may 
become difficult. To avoid this difficulty, we sometimes use the wind data at ranges of $110-225 \mathrm{~km}$ corresponding to the horizontal separations of $63-206 \mathrm{~km}$ between the lidar and radar fields of view.

\section{Results and Discussion}

In 1985, the radar was mainly used as an auroral radar to investigate the $E$-region irregularities and somewhat sporadically as a meteor radar. On the other hand, the lidar measurements were made on 42 nights during the period from April to October (NOMURA et al., 1987). As a result, the number of simultaneous measurements was not large. We discuss here six examples obtained on May 28-29, August 5-9 and August 16-17, 1985, for which both the meteor radar and lidar measurements continued at least for 8 hours and gravity wave activities were recognized to some extent. Note that $\mathrm{LT}=\mathrm{UT}+3$ hours.

\subsection{May 28-29, 1985}

The first example taken on the night of May 28, 1985 is shown in Figs. 1 and 2. The ionospheric $E$-region during the measurement was so quiet that the meteor echoes were not contaminated with auroral echoes. The time variation of the sodium abundance is shown on the bottom in Fig. 1, where the dashed curve represents the smoothed abundance variation having periods longer than 3 hours. It can be seen that the abundance also fluctuates with periods of approximately 1-2 hours. For this observation (see Fig. 2), by calculating the difference between the normalized sodium profile averaged over one hour and the profile averaged over the night, NOMURA et al. (1987) have found upward-propagating, monochromatic gravity waves with a period of 3 to 4 hours and with a vertical wavelength of about $10 \mathrm{~km}$, accordingly with a vertical phase velocity of about $0.8 \mathrm{~m} / \mathrm{s}$.

The time variation of all the wind velocities observed at altitudes $(H)$ of 70-120 $\mathrm{km}$ and at slant ranges $(R)$ of $110-600 \mathrm{~km}$ by two (GGS and GMS) radar beams is shown in the top part in Fig. 1. Since the GGS beam measures a north-south (N-S) component of wind velocity and the GMS beam an NW-SE component, the velocities plotted can be approximately regarded as those of the $\mathrm{N}-\mathrm{S}$ components. It is noted that the measured line-of-sight velocity is converted to the horizontal velocity by neglecting vertical wind motion because vertical motion is usually far smaller than horizontal motion. As has been described in Section 2, our antenna beamwidth in the horizontal plane is much narrower (about $4^{\circ}$ ) compared to the beamwidth of a usual meteor radar, so that the detection rate of meteor echoes is low, say, a few to 10 echoes per hour. Since the wind velocity in the top part in Fig. 1 exhibits random-like time variation, at first glance it seems impossible to discover any gravity waves. This time variation may stem from a relatively large field of view (530 km in horizontal length) of the radar; when horizontal wavelengths of gravity waves are comparable to or smaller than, say, $500 \mathrm{~km}$ and also meteor echoes are randomly detected along the radar range, a random-like time variation of the observed wind velocity as shown in Fig. 1 can be expected. 


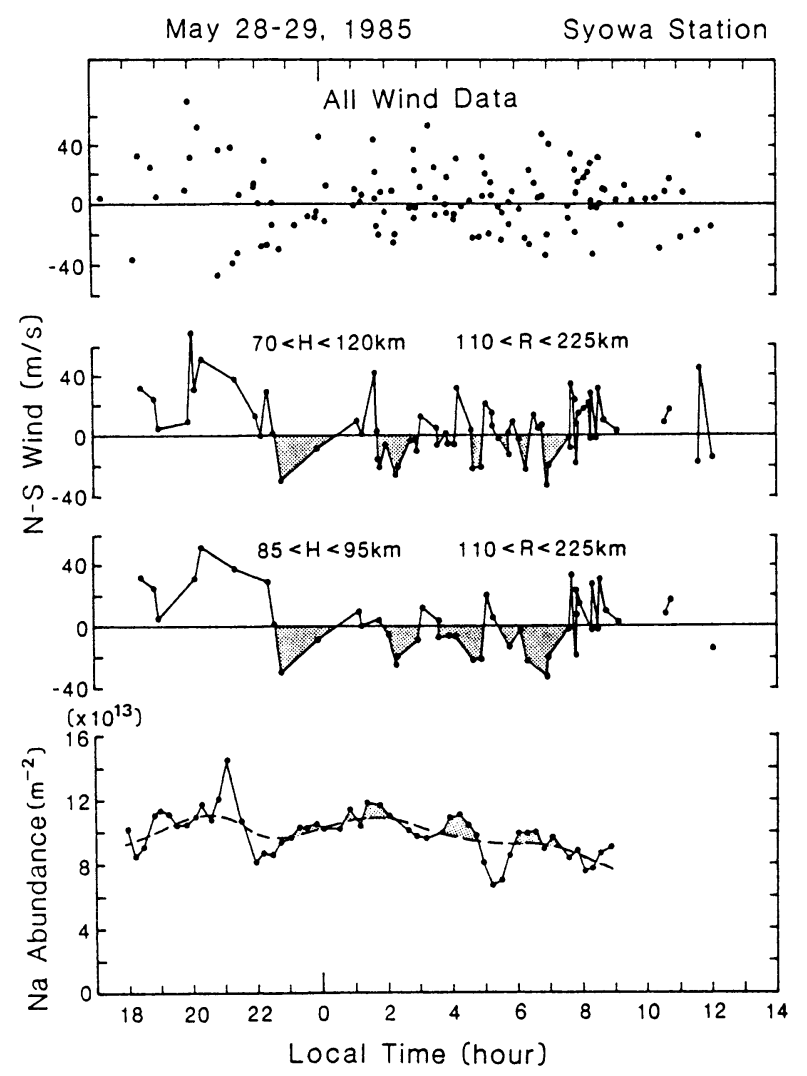

Fig. 1. Time variations of north-south wind velocity (top, second and third) and sodium abundance (bottom) on May 28-29, 1985. The top figure plots all wind velocity data at altitudes of $70-120 \mathrm{~km}$ and slant ranges of 110-600 km, while the second and third figures plot velocities at limited altitudes $(H)$ and slant ranges $(R)$ as indicated in the figure. The dashed curve superposed upon the abundance represents the smoothed variation.

In order to see an ordered time variation, only the wind velocities satisfying the conditions of both $70<H<120 \mathrm{~km}$ and $110<R<225 \mathrm{~km}$ and of both $85<H<95 \mathrm{~km}$ and $110<R<225 \mathrm{~km}$ were selected, the results of which are shown in the second and third parts, respectively, in Fig. 1. Time variation in the third part more clearly exhibits wavelike structure than that in the second part. This structure can be ascribed to the gravity waves with periods of 1-2 hours. Also recognized on this structure, albeit implicitly, are the waves with periods longer than 3 hours which give the slowly-varying component of the wind velocity. These longer waves may correspond to the dashed curve of the sodium abundance in Fig. 1 and also to the wave found by NOMURA et al. (1987). These points will be discussed later in more detail. 

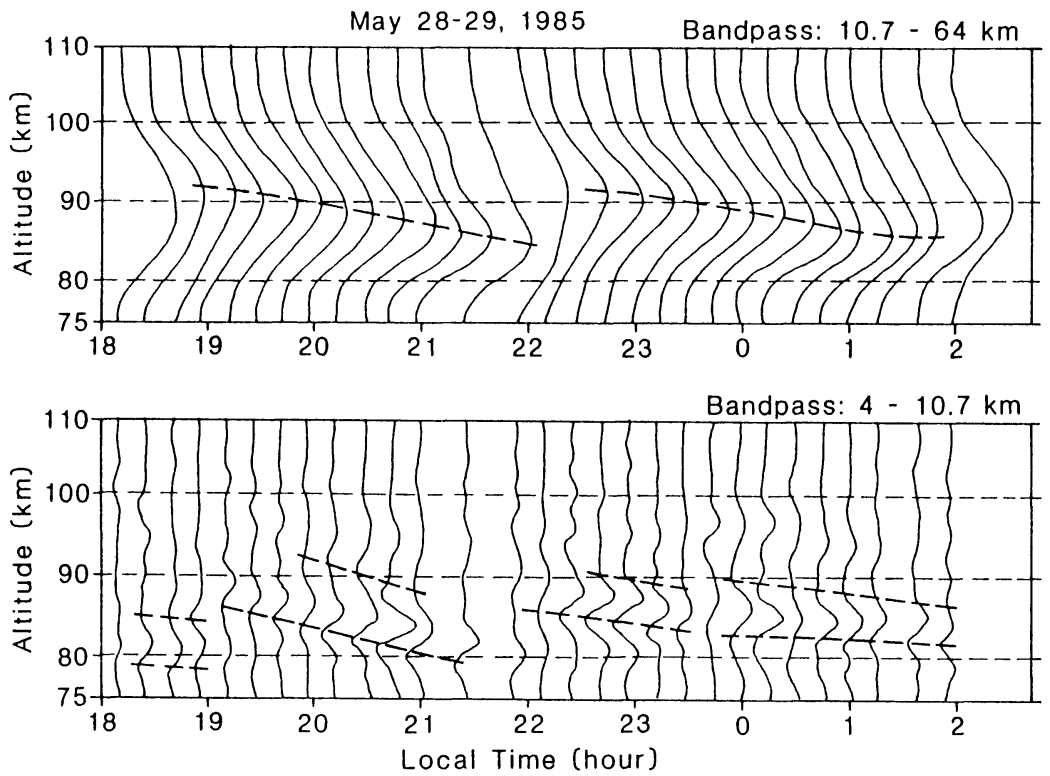

(a)
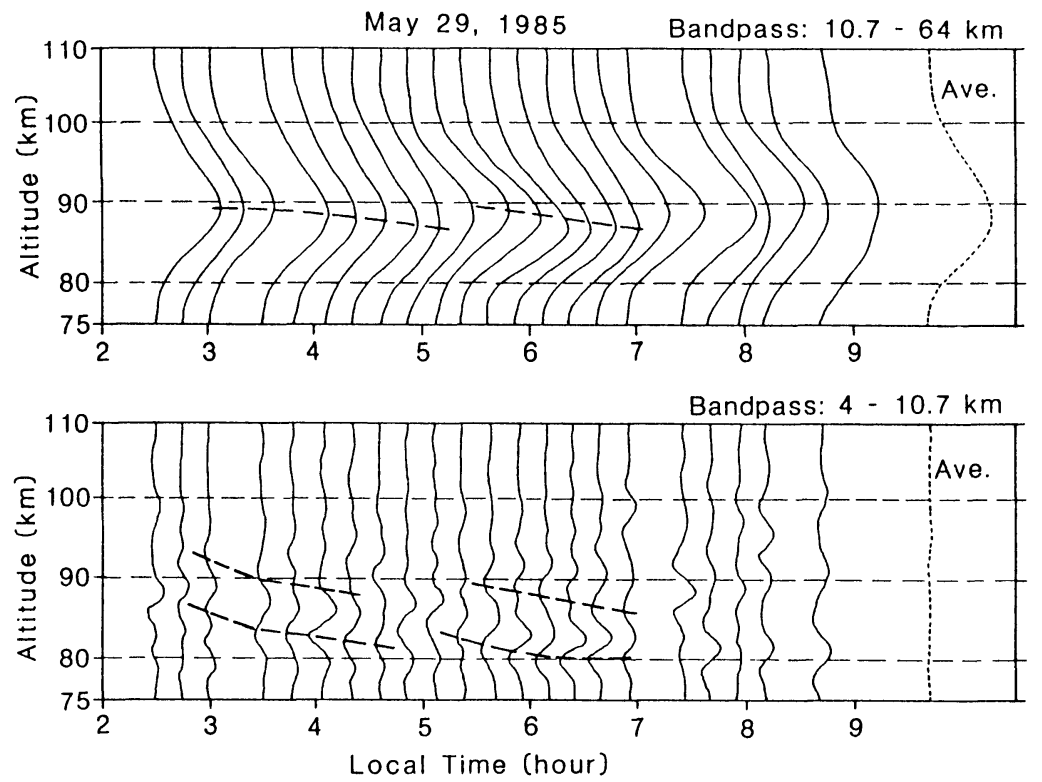

(b)

Fig. 2. (a) Sodium density profiles observed on May 28-29, 1985. Profiles in the upper and lower parts are band-pass filtered between 10.7 and $64.0 \mathrm{~km}$ and between 4.0 and $10.7 \mathrm{~km}$, respectively, in vertical wavelength. All profiles are normalized so that each has the same abundance. The dashed oblique lines indicate apparent phase progression. (b) Continuation of Fig. 2(a). Profiles averaged over the night are also shown by the dotted curve. 
From a comparison between the top and third parts in Fig. 1, it may be said that the shorter-period waves have horizontal wavelengths smaller than about 500 $\mathrm{km}$ and longer than $200 \mathrm{~km}$. If the wavelengths were far longer than $500 \mathrm{~km}$, the wind velocities in the top part would be ordered, and if they were far shorter than $200 \mathrm{~km}$, the velocities in the third part would become more random. From a very simplified polarization relation of gravity wave (HINES, 1960), $\lambda_{x} / \lambda_{z} \simeq T / T_{\mathrm{b}}$ where $\lambda_{x}$ is the horizontal wavelength, $\lambda_{z}$ the vertical wavelength, $T$ the wave period and $T_{\mathrm{b}}$ the Brünt-Väisälä period, $\lambda_{x}$ can be estimated. By taking $\lambda_{z} \simeq 10 \mathrm{~km}$ (NOMURA et al., 1987), $T_{\mathrm{b}} \simeq 5$ minutes and $T=60-120$ minutes (the third part in Fig. 1), $\lambda_{x}$ becomes $120-240 \mathrm{~km}$, which is consistent with the rough estimation described above. It is important to point out that the short-period ( $<2$ hours) structure in the wind velocity is similar to that in the sodium abundance, especially during 22:00-08:00 LT; roughly speaking, when the abundance increases beyond the dashed curve, the wind motion seems to be directed southward.

Figures 2(a) and 2(b) show the sodium density profiles about every 15 minutes processed by a bandpass filtering of the observed profile between 10.7 and $64.0 \mathrm{~km}$ and between 4.0 and $10.7 \mathrm{~km}$, respectively, in vertical wavelength. All the profiles are normalized so that each has the same abundance. As indicated by the dashed oblique lines in the upper parts of Figs. 2(a) and 2(b), the gravity waves with downward phase progression having periods of 2-4 hours are clearly seen on the bottomside of the layer (CHIU and CHING, 1978). These waves undoubtedly correspond to the long-period variation of the sodium abundance (dashed curve in Fig. 1). As indicated by the dashed oblique lines in the lower parts in Figs. 2(a) and 2(b), short-period (1-2 hours) waves with vertical wavelengths less than $10 \mathrm{~km}$ are observed together with the long-period waves. These waves correspond to the shortperiod fluctuations of both the sodium abundance and wind velocity in Fig. 1.

In order to discover the dominant wave periods causing the fluctuations, frequency spectrum analyses of the wind velocity, sodium abundance and sodium density were carried out. For this purpose, we generated new data points with 15-min intervals by means of a polynomial fitting to three successive measured data points with random time intervals, and then Fourier-analyzed the generated data. The results appear in Fig. 3 where the frequency spectra of the wind velocity and sodium abundance (top part) and of the sodium densities at 95, 90 and $85 \mathrm{~km}$ (second, third and bottom parts, respectively) bandpass-filtered between 10.7 and $64.0 \mathrm{~km}$ and between 4.0 and $10.7 \mathrm{~km}$ in vertical wavelength (see Fig. 2) are displayed. Fairly high correlations among the spectral peaks around 70, 90, 110 and 140 minutes of the wind velocity, sodium abundance and sodium density spectra are discernible. A spectral peak of the wind velocity appearing around 200 minutes has clear counterparts in the density spectra but does not have a corresponding peak in the sodium abundance spectrum. Anyhow, it can be concluded that the gravity waves with a variety of periods are well manifested in the wind velocity, sodium abundance and sodium density fluctuations. 


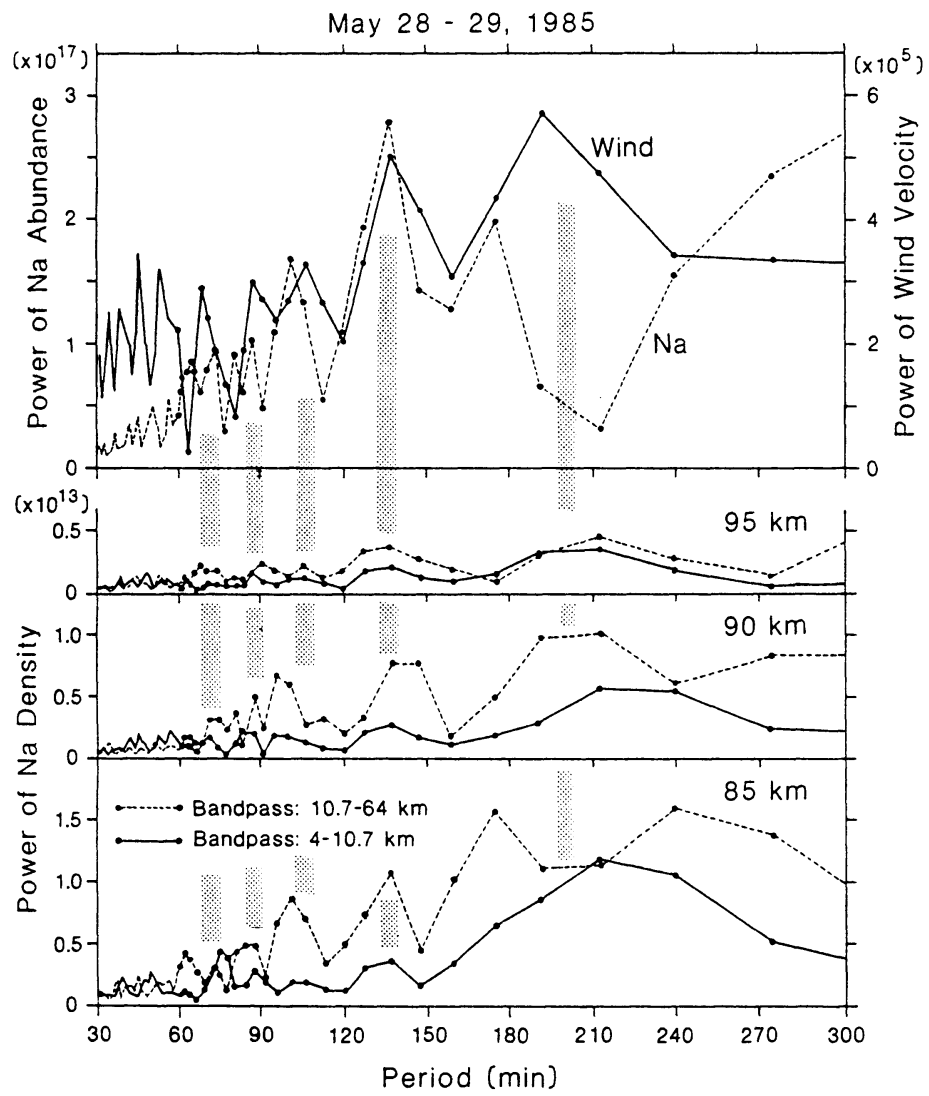

Fig. 3. Frequency spectra of wind velocity and sodium abundance (top) and sodium densities at 95, 90 and $85 \mathrm{~km}$ (second, third and bottom, respectively) bandpass-filtered between 10.7 and $64.0 \mathrm{~km}$ (dashed curves) and between 4.0 and $10.7 \mathrm{~km}$ (solid curves) in vertical wavelength on May 28-29, 1985.

\subsection{August 8-9, 1985}

Second example obtained on the night of August 8, 1985 is shown in Figs. 4 and 5. As can be seen in Fig. 4 , the geomagnetic $H$-component at Syowa Station was disturbed during 01:00-07:00 LT, during which auroral $E$-region echoes were observed three times as indicated by the horizontal bars. The meteor echoes contaminated by auroral echoes were carefully examined, and only reliable wind velocity data are plotted in Fig. 4. A wavelike structure with periods of 1-2 hours is clearly seen on the sodium abundance. The short-period (1-2 hours) fluctuation amplitudes of both the wind velocity $(\sim 40 \mathrm{~m} / \mathrm{s})$ and abundance $\left(2 \times 10^{13} \mathrm{~m}^{-2}\right.$, or $40 \%$ of the background) are larger than those of the first example in Fig. 1. Although not so clear, the abundance seems to increase when the wind motion is northward, 


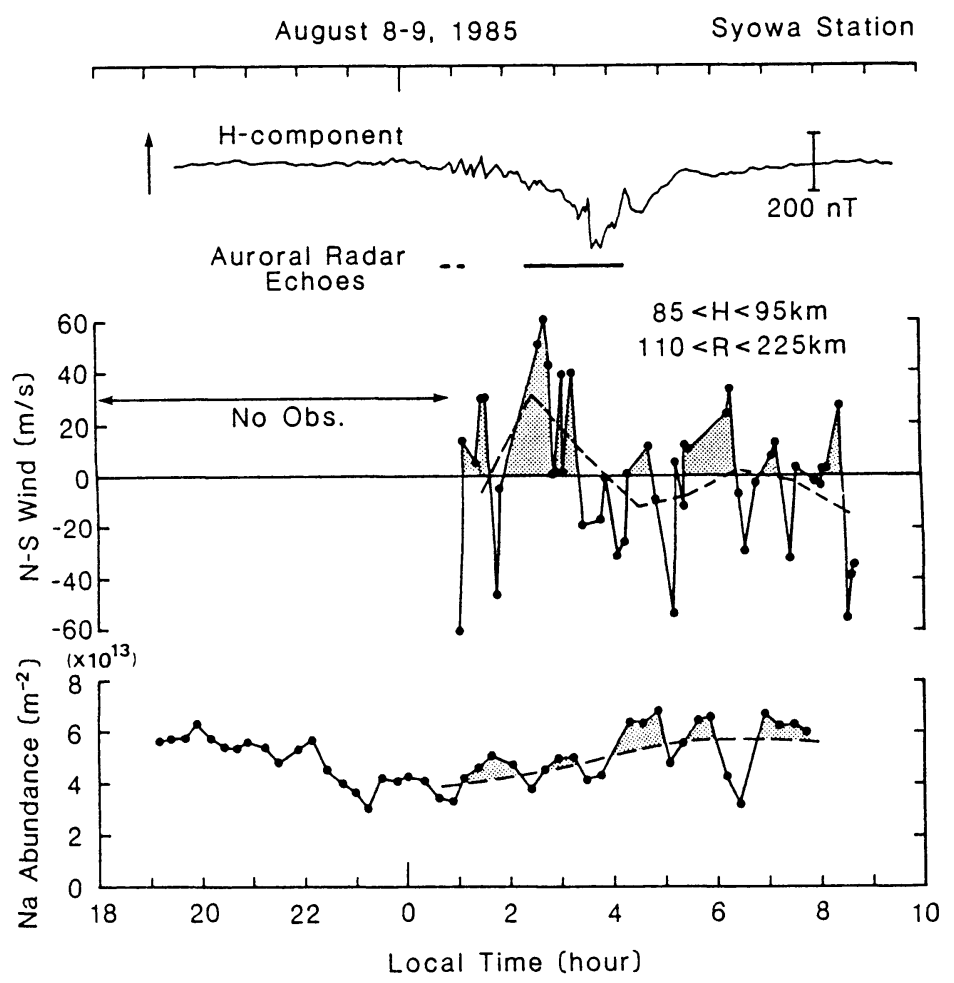

Fig. 4. Time variations of the geomagnetic $H$-component at Syowa Station (top), north-south wind velocity (middle) and sodium abundance (bottom) on August 8-9, 1985. The dashed curves superposed upon the middle and bottom figures represent hourly-averaged and smoothed variations, respectively. The periods of auroral echo occurrence are shown by horizontal bars. The positive direction of the $H$-component is indicated by the vertical arrow.

whereas for the case of May 28-29 (Fig. 1) it increases when the wind motion is southward. This difference may be simply due to the difference in the viewing areas of the radar and lidar; since both areas are horizontally separated by $63-200 \mathrm{~km}$, wind velocity in the lidar field of view may be out of phase with that in the meteor radar field of view if the wavelength of the gravity wave is of the order of $200 \mathrm{~km}$. Corresponding to the gradual increase in the sodium abundance (dashed curve), the hourly-averaged wind velocity (dashed line) gradually changes its direction from northward to southward.

Figure 5 shows the sodium density profiles using the same format as that of Fig. 2. The activity of the long-period (2-3 hours) gravity waves is easily discernible in the upper part in Fig. 5. The short-period (1-2 hours) waves with vertical wavelength of about $5 \mathrm{~km}$ seem to appear more regularly than those in Figs. 2(a) and 2(b). This contrast may explain the more sinusoidal-like fluctuation of the abundance in Fig. 4 compared with the abundance fluctuation in Fig. 1. 

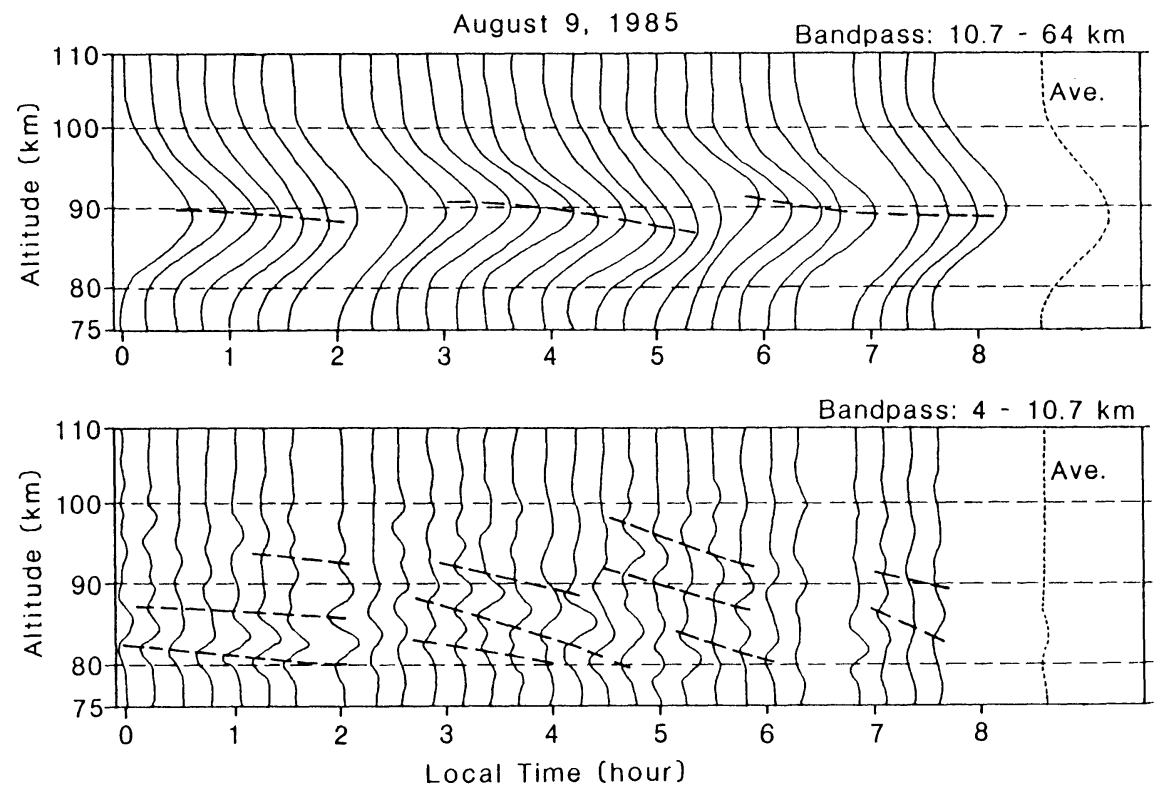

Fig. 5. Same as Fig. 2(a) but for August 9, 1985. Profiles averaged over the night are also shown by the dotted curve.

Frequency spectra of the wind velocity, sodium abundance and sodium density are displayed in Fig. 6 using the same format as that of Fig. 3. The correlations between the wind velocity spectral peaks $(60,100$ and 160 minutes; vertical bars with light gray) and the sodium abundance peaks (80,105, 130 and 160 minutes; vertical bars with dark gray) are worse than those in Fig. 3. The wind velocity spectrum is, however, very similar to the sodium density spectra with vertical wavelengths of $4.0-10.7 \mathrm{~km}$; note the corresponding spectral peaks around 100 and 160 minutes in these spectra. On the other hand, the sodium abundance spectrum is very similar to the sodium density spectra with vertical wavelengths of $10.7-64.0 \mathrm{~km}$. Such behaviors are in contrast to the results observed in Fig. 3, where almost identical spectral peaks appear in all the spectra. Thus, Fig. 6 indicates that the wind velocity response to gravity waves is not simply related to the sodium layer response.

\subsection{August 5-9, 1985}

Successive simultaneous measurements were made on the 4 nights of August 5-8, 1985 (NomURA et al., 1989). The results are shown in Fig. 7, where hourlyaveraged wind velocity instead of individual velocities is plotted together with the abundance variation. Using Fig. 7, we examine qualitatively longer-period $(>3$ hours) waves appearing in the wind velocity and abundance.

On the night of August 6, the time variation (approximately 3-hour period) of the hourly wind velocity during 21:00-04:00 LT is very similar to that of the sodium 


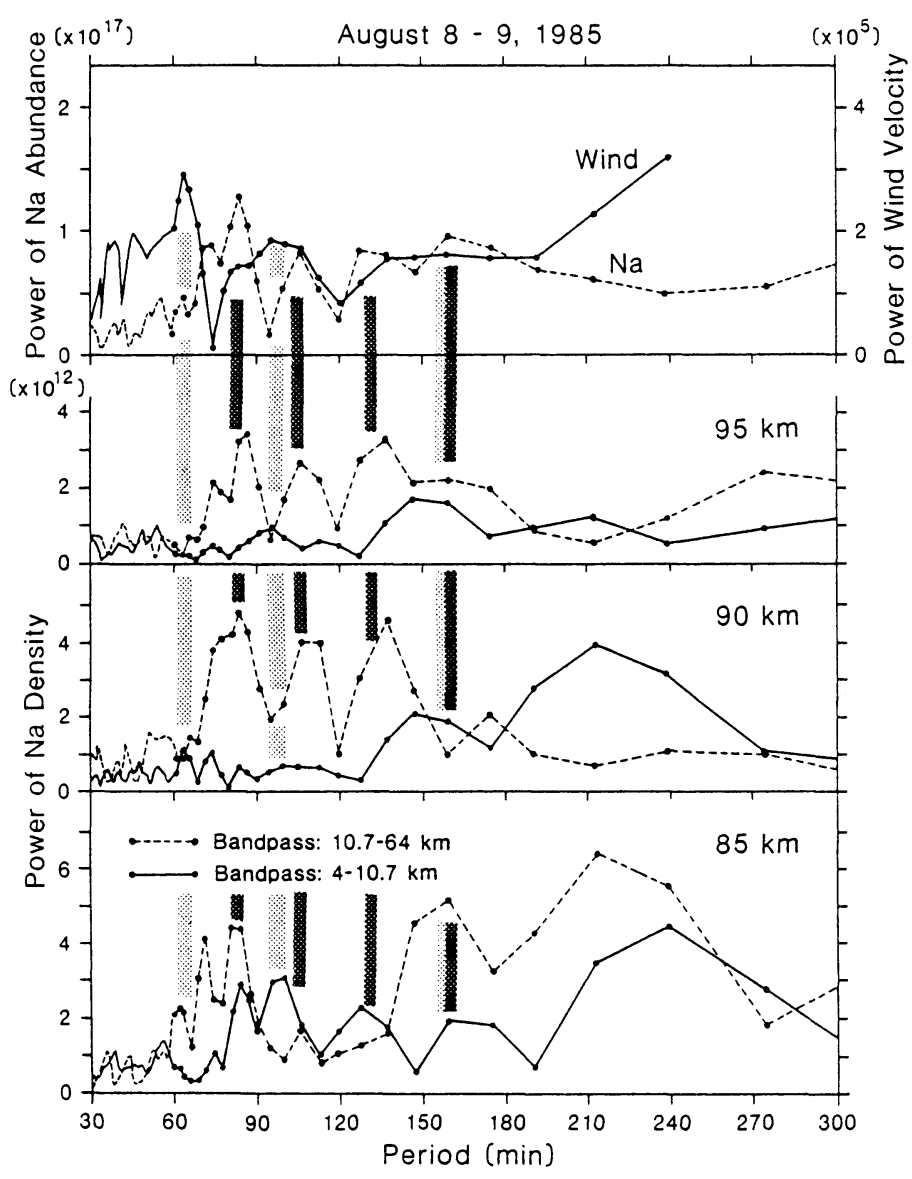

Fig. 6. Same as Fig. 3 but for August 8-9, 1985.

abundance; the abundance increased in harmony with the increase in northward wind velocity. A time displacement of about one hour between the long-period $(\sim 6$ hours) abundance and velocity variations was observed during 00:00-08:00 LT on the night of August 7. In contrast, on the nights of August 5 and 8, the abundance increased gradually while the wind gradually changed its predominant direction from north to south. Thus, Figure 7 demonstrates variabilities of a phase relationship between the long-period fluctuations of the wind velocity and sodium abundance.

\subsection{August 16-17, 1985}

NomURA et al. (1987) have reported a sodium layer response to the auroral substorm which took place on the morning of June 1, 1985. It was quite a rare 


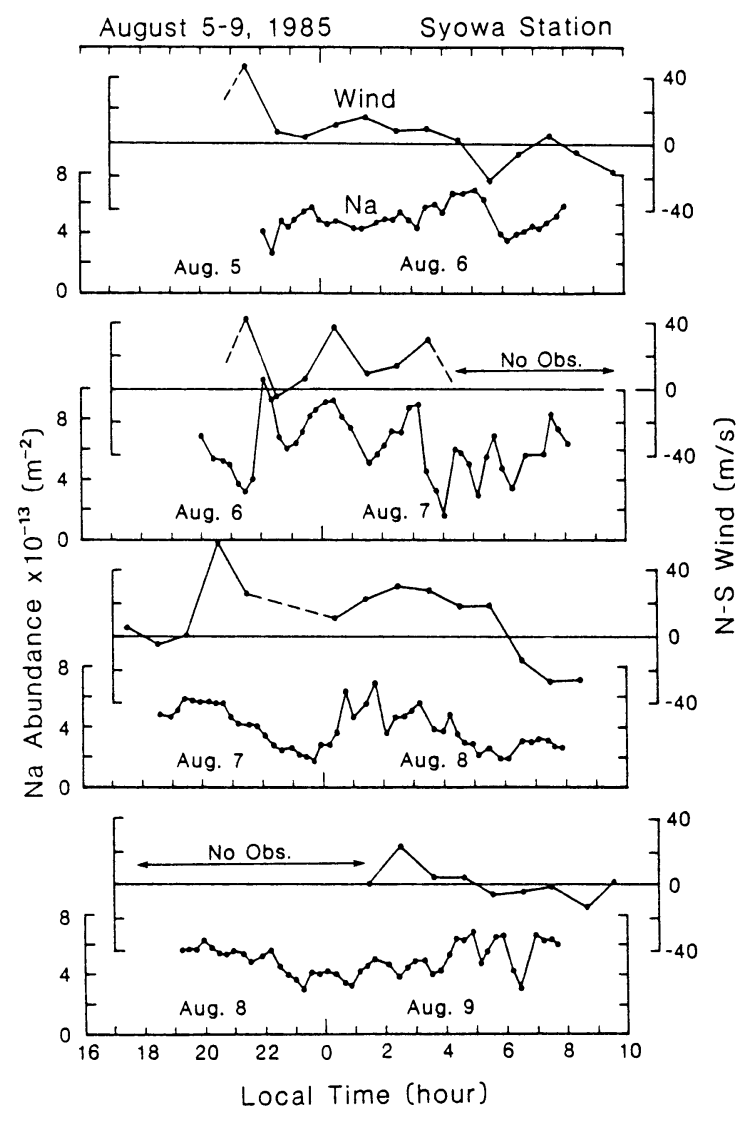

Fig. 7. Time variations of the hourly-averaged north-south wind velocity and sodium abundance during August 5-9, 1985.

opportunity to observe sodium layer disturbance due to auroral breakup. They found that in accord with the auroral breakup, the abundance starts to decrease and the layer starts to be compressed from the upper part. A detailed physical process explaining these interesting behaviors is not yet clear.

A medium-scale substorm $\left(\Delta H_{\max }=500 \mathrm{nT}\right)$ happened on the night of August 16,1985 . The hourly wind velocity and sodium abundance for this event are plotted in Fig. 8 together with the geomagnetic $H$-component. The substorm started around 01:20 LT, after which a strong northward wind attaining a maximum of $60 \mathrm{~m} / \mathrm{s}$ appeared. As soon as the $H$-component subsided around 03:00 LT, the wind velocity returned to the quiet value. The sudden increase in the wind velocity may be related to ionospheric electric fields which can modify neutral winds when strong electric fields penetrate toward lower altitudes $(85-95 \mathrm{~km})$. REID (1983) has theorized that meteor trail drift may deviate from a neutral wind if a strong electric field exists. 

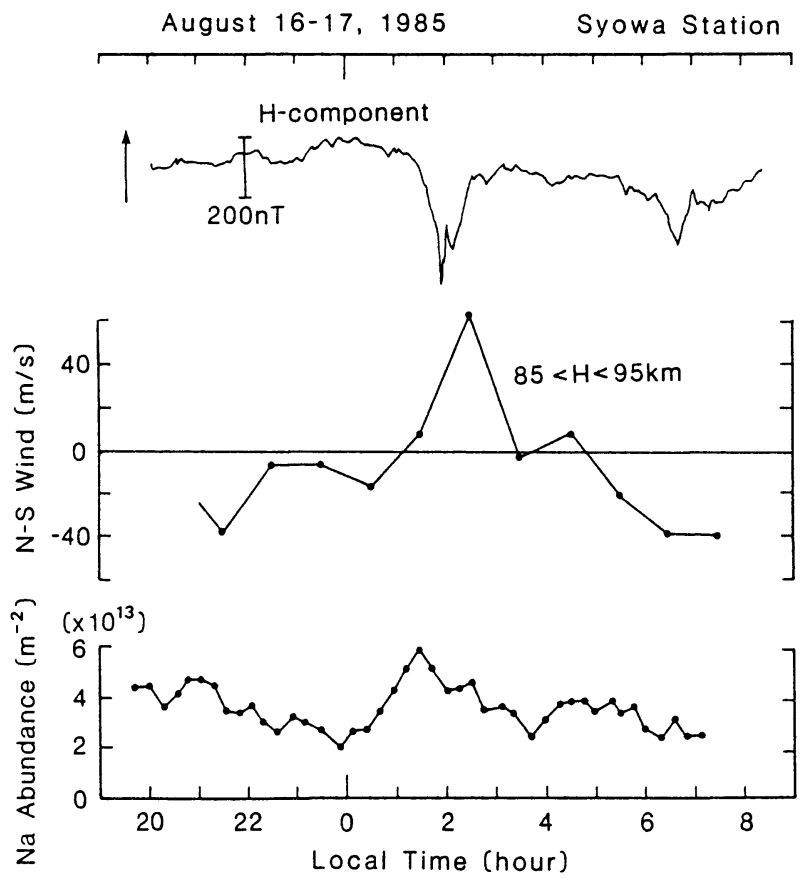

Fig. 8. Time variations of the geomagnetic $H$-component at Syowa Station (top), hourly-averaged north-south wind velocity (middle) and sodium abundance (bottom) on August 16-17, 1985. The positive direction of the $H$-component is indicated by the vertical arrow.

Using the meteor radar at Syowa Station, OGAWA et al. (1985) have presented examples showing that wind velocities sometimes exceeded $100 \mathrm{~m} / \mathrm{s}$ during disturbed ionospheric conditions. PRIKRYL et al. (1986) have demonstrated from a bistatic $50 \mathrm{MHz} \mathrm{CW}$ radar that meteor drifts near midnight for disturbed days were predominantly equatorward with velocities up to $100 \mathrm{~m} / \mathrm{s}$ and were well correlated with the simultaneous $E$-region auroral drifts $(\boldsymbol{E} \times \boldsymbol{B}$ drifts $)$ measured at some $10 \mathrm{~km}$ higher altitude.

In Fig. 8, the wind velocities at the maximum substorm phase have an equatorward component, being consistent with the result of PRIKRYL et al. (1986), and the sodium abundance starts to decrease in accord with the onset of the substorm, which agrees qualitatively with the observation by NOMURA et al. (1987).

A weaker substorm $\left(\Delta H_{\max }=200 \mathrm{nT}\right)$ occurred on August 9 (see Fig. 4). In this case, the wind velocity and abundance were not affected by the substorm. This may be attributable to the weakness of the substorm, and therefore to no penetration of ionospheric electric fields toward lower altitudes. 


\section{Summary}

Simultaneous measurements of the high-latitude upper mesospheric gravity waves by the meteor radar and lidar systems at Syowa Station have been described. The results from the 6 night measurements in 1985 can be summarized as follows:

1) The short-period (1-2 hours) and long-period ( $>2$ hours) fluctuations of the north-south wind velocity measured by the meteor radar have counterparts in the sodium abundance and profile measured by the lidar. From spectral analysis it is found that on the night of May 28, the spectral peaks appearing in the wind velocity, sodium abundance and sodium density are almost identical, while on the night of August 8 the wind velocity spectrum is very similar to the sodium density spectra with vertical wavelengths of $4.0-10.7 \mathrm{~km}$.

2) As a peculiar effect on the upper mesosphere in the auroral zone, both wind velocity and sodium abundance (therefore, the sodium density profile) may be modified by substorm activity. An example obtained on the night of August 16, 1985 indicates that during a medium-scale substorm a strong equatorward wind having a maximum velocity of $60 \mathrm{~m} / \mathrm{s}$ appeared and sodium abundance gradually decreased. The degree of modification seems to be dependent on electric fields associated with the substorm. A mechanism explaining this peculiar decrease in the abundance, however, is unknown. In addition to the dynamical process associated with electric fields, chemical processes induced by high-energy particles precipitating from the magnetosphere must also be considered in understanding responses of the sodium layer to auroral substorms.

Until now, upper mesospheric gravity waves have been observed almost exclusively by one technique (lidar, radar including meteor radar, or others). The simultaneous measurement results described here indicate that the response of the neutral winds to gravity waves is fundamentally consistent with the sodium layer response. Unfortunately, the detection number of meteor echoes per hour was not large because of both the sharpness of the azimuthal radar beamwidth and the frequent contamination of meteor echoes by auroral echoes, and therefore we cannot discuss more detailed comparisons between the wind velocity and sodium layer responses to gravity waves. It should also be noted that since our meteor radar can observe mainly north-south wind components, the role of east-west components in our results cannot be estimated.

We would like to thank the staff of the National Institute of Polar Research and the wintering members of the 26th Japanese Antarctic Research Expedition (1985-1986) for their kind support to the experiment. We also thank the anonymous reviewers for giving valuable comments on the manuscript. 


\section{REFERENCES}

Avery, S. K. and D. Tetenbaum, Simultaneous sodium and wind measurements in the upper mesosphere using the Urbana meteor radar and lidar systems, J. Atmos. Terr. Phys., 45, 753-764, 1983.

Chiu, Y. T. and B. K. Ching, The response of atmospheric and lower ionospheric layer structures to gravity waves, Geophys. Res. Lett., 5, 539-542, 1978.

FRITTS, D. C., Gravity wave saturation in the middle atmosphere: A review of theory and observations, Rev. Geophys. Space Phys., 22, 275-308, 1984.

Gardner, C. S. and J. D. Shelton, Density response of neutral atmospheric layers to gravity wave perturbations, J. Geophys. Res., 90, 1745-1754, 1985.

Gardner, C. S. and D. G. Voelz, Lidar studies of the nighttime sodium layer over Urbana, Illinois, 2. Gravity waves, J. Geophys. Res., 92, 4673-4694, 1987.

Geller, M. A., Dynamics of the middle atmosphere, Space Sci. Rev., 34, 359-375, 1983.

Hines, C. O., Internal atmospheric gravity waves at ionospheric heights, Can. J. Phys., 38, 1441-1481, 1960.

Igarashi, K., T. Ogawa, M. Ose, R. Fujil, and T. Hirasawa, A new VhF Doppler radar experiment at Syowa Station, Antarctica, Mem. Natl. Inst. Polar Res., Spec. Issue, 22, 258-267, 1982.

MeEK, C. E., I. E. ReID, and A. H. MAnson, Observations of mesospheric wind velocities, 1. Gravity wave horizontal scales and phase velocities determined from spaced wind observations, Radio Sci., 20, 1363-1382, 1985.

Nomura, A., T. Kano, Y. Iwasaka, H. Fukunishi, T. Hirasawa, and S. Kawaguchi, Lidar observations of the mesospheric sodium layer at Syowa Station, Antarctica, Geophys. Res. Lett., 14, 700-703, 1987.

Nomura, A., Y. Iwasaka, H. Fukunishi, T. Hirasawa, S. Kawaguchi, and T. Kano, Dynamics of the mesospheric sodium layer in Antarctica: Lidar measurements at Syowa Station, 1985, Proc. NIPR Symp. Upper Atmos. Phys., 1, 75-83, 1988.

Nomura, A., Y. Imasaka, and T. Kano, Gravity wave activities over Syowa Station, Antarctica, Proc. NIPR Symp. Polar Meteorol. Glaciol., 2, 1989 (in press).

Ogawa, T., K. Igarashi, Y. Kuratani, R. Fujil, and T. Hirasawa, Some initial results of $50 \mathrm{MHz}$ meteor radar observation at Syowa Station, Mem. Natl. Inst. Polar Res., Spec. Issue, 36, 254-263, 1985.

Prikryl, P., J. A. Koehler, and G. J. Sofko, Simultaneous CW radio measurements of meteor and auroral drifts, Radio Sci., 21, 271-282, 1986.

REID, G. C., The influence of electric fields on radar measurements of winds in the upper mesosphere, Radio Sci., 18, 1028-1034, 1983.

RowLETT, J. R. and C. S. GARDNER, Lidar observations of wave-like structure in the atmospheric sodium layer, Geophys. Res. Lett., 5, 683-686, 1978. 